Chapman University

Chapman University Digital Commons

Pharmacy Faculty Articles and Research

School of Pharmacy

9-2006

\title{
Silica-Coated Lanthanum-Strontium Manganites for Hyperthermia Treatments
}

Vuk Uskoković

ChapmanUniversity, uskokovi@chapman.edu

Aljoša Košak

Jožef Stefan Institute

Miha Drofenik

Jožef Štefan Institute

Follow this and additional works at: http://digitalcommons.chapman.edu/pharmacy_articles

Part of the Medical Biochemistry Commons, Other Chemistry Commons, and the Physical Chemistry Commons

\section{Recommended Citation}

Uskoković, V., Košak, A., Drofenik, M., 2006. Silica-coated lanthanum-strontium manganites for hyperthermia treatments. Materials Letters 60, 2620-2622. doi:10.1016/j.matlet.2006.01.047

This Article is brought to you for free and open access by the School of Pharmacy at Chapman University Digital Commons. It has been accepted for inclusion in Pharmacy Faculty Articles and Research by an authorized administrator of Chapman University Digital Commons. For more information, please contact laughtin@chapman.edu. 


\section{Silica-Coated Lanthanum-Strontium Manganites for Hyperthermia Treatments}

\section{Comments}

NOTICE: this is the author's version of a work that was accepted for publication in Materials Letters. Changes resulting from the publishing process, such as peer review, editing, corrections, structural formatting, and other quality control mechanisms may not be reflected in this document. Changes may have been made to this work since it was submitted for publication. A definitive version was subsequently published in Materials Letters, volume 60, in 2006. DOI: 10.1016/j.matlet.2006.01.047

The Creative Commons license below applies only to this version of the article.

\section{Creative Commons License}

\section{(c) 1 (1) 90}

This work is licensed under a Creative Commons Attribution-Noncommercial-No Derivative Works 4.0 License.

\section{Copyright}

Elsevier 


\title{
Silica-Coated Lanthanum-Strontium Manganites for Drug Delivery and Hyperthermia Treatments
}

\author{
Vuk Uskoković ${ }^{1}$, Aljoša Košak ${ }^{1}$, Miha Drofenik ${ }^{1,2}$ \\ ${ }^{1}$ Advanced Materials Department, Jožef Stefan Institute, Ljubljana, Slovenia \\ ${ }^{2}$ Faculty of Chemistry and Chemical Engineering, Maribor, Slovenia
}

Corresponding Author: vuk.uskokovic@ijs.si

\begin{abstract}
$\mathrm{La}_{0.76} \mathrm{Sr}_{0.24} \mathrm{MnO}_{3+\delta}$ particles, prepared by performing a traditional, solid-state method of synthesis, were coated by uniform layers of silica via initiating hydrolysis and condensation of TEOS in aqueous-alcoholic alkali environment. The eventually obtained samples exhibited Curie temperature at $\sim 40{ }^{\circ} \mathrm{C}$, and comprised core-shell particles of $250 \mathrm{~nm}$ in diameter. By varying stoichiometric ratio of cations within manganite cores of the particles, Curie point of the resulting material can be varied too, thus opening a way for the simple design of biocompatible, temperature-self-regulating particles for application in hyperthermia treatments, with Curie point thereof adjusted to a destined biological context of application.
\end{abstract}

\section{Introduction}

LaSr-manganites are promising and widely used magnetic ceramics of today, due to wide range of actually and potentially co-existing inherent properties thereof, including competing ferromagnetic metallic and antiferromagnetic insulating phases with the strong corresponding transition at Curie temperature $\left(\mathrm{T}_{\mathrm{c}}\right)$, exceptional magnetotransport and magnetoelastic properties, half-metallicity of the electron bands, electric field polarizability and its effect on transport properties, etc. However, our present work is being framed by a novel idea of developing LaSr-manganites for in vivo application in biomedicine. Simply predictable dependence of Curie point of the material on its stoichiometric formula, has served as the key-stone fact for building the present investigations. Materials with $\mathrm{T}_{c}$ in the close range of hyperthermia treatments, can be used as auto-regulating power-absorbing and temperature-controlling magneticallyguided drug delivery systems [1,2], enabling selective targeting of malignant tissues, known to be more vulnerable to increased temperatures comparing to healthy and more flexibly developed tissues [3].

\section{Experimental}

The procedure for synthesis of silica-coated LaSr-manganite particles, exhibiting $\mathrm{T}_{\mathrm{C}}$ at $\sim 40{ }^{\circ} \mathrm{C}$, is as follows. Stoichiometric mixture of $\mathrm{Mn}_{3} \mathrm{O}_{4}, \mathrm{La}_{2} \mathrm{O}_{3}$ and $\mathrm{SrCO}_{3}$, set to obtain $\mathrm{La}_{0.76} \mathrm{Sr}_{0.24} \mathrm{MnO}_{3+\delta}$ as the final composition, was homogenized by grinding in a $\mathrm{YZrO}_{2}$ planetary ball mill at $300 \mathrm{rpm}$ for $2 \mathrm{~h}$. The obtained powder was pressed at 0.175 $\mathrm{GPa}$, calcined at $1200{ }^{\circ} \mathrm{C}$ for $2 \mathrm{~h}$ in air, and subsequently milled for $4 \mathrm{~h}$ under the same conditions as when starting homogenization had been performed. With the respective milling, average particle size decreased from 400 to $100 \mathrm{~nm}$, as was calculated from 
specific-surface area measurements. $80 \mathrm{mg}$ of the collected powder was, then, dispersed in $100 \mathrm{ml}$ of $1.7-\mathrm{M}$ concentrated (25\%wt) aqueous ammonia solution in 2-propanol at 40 ${ }^{\circ} \mathrm{C}$. Tetraethylorthosilicate (TEOS) in concentration of $4.5 \mathrm{mmol} / \mathrm{l}$ was poured in tightly capped container of the dispersion, which was let aged for $20 \mathrm{~h}$ more. The resulting solid phase was collected using magnetic decantation, and dried at $70^{\circ} \mathrm{C}$. XRD pattern of the obtained powder, evidencing the presence of perovskite structure of the manganite compound within the sample, is shown in Fig. 1. By varying the stoichiometric ratio of constitutive cations in the starting mixture of precursor oxides and Sr-carbonate, LaSrmanganites with different stoichiometric formulae and different $T_{c}$ values were prepared.

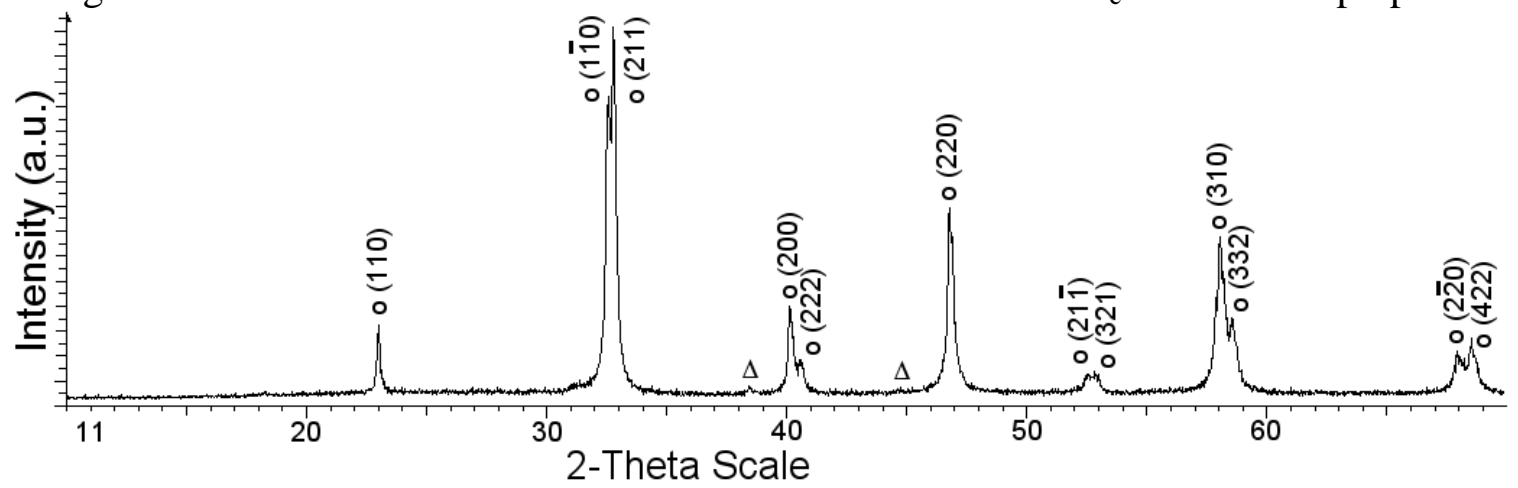

Fig. 1. XRD pattern of the synthesized silica-coated $\mathrm{La}_{0.76} \mathrm{Sr}_{0.24} \mathrm{MnO}_{3+\delta}$ sample. Manganite perovskite diffraction peaks are denoted with an "o", whereby Al peaks originating from the powder holder, are denoted with an " $\Delta$ ".

\section{Results and discussion}

In Fig. 2, where specific magnetization vs. measuring temperature dependencies for the synthesized $\mathrm{x}=0.16, \mathrm{x}=0.24, \mathrm{x}=0.33$, and $\mathrm{x}=0.5$ LaSr-manganite samples, calcined at $1200{ }^{\circ} \mathrm{C}$, are laid out, one can see a directly proportional dependence of $T_{c}$ of the material on its stoichiometric content of $\mathrm{Sr}$, described by parameter " $\mathrm{x}$ " in $\mathrm{La}_{1}$ ${ }_{\mathrm{x}} \mathrm{Sr}_{\mathrm{x}} \mathrm{MnO}_{3+\delta}$ formula. With increase in parameter " $\mathrm{x}$ " from 0.16 to 0.24 to 0.33 to $0.5, \mathrm{~T}_{\mathrm{C}}$ increases from $25^{\circ} \mathrm{C}$ to $60{ }^{\circ} \mathrm{C}$ to $90{ }^{\circ} \mathrm{C}$ to $100{ }^{\circ} \mathrm{C}$, respectively, as is presented in Fig. $2 \mathrm{~b}$.

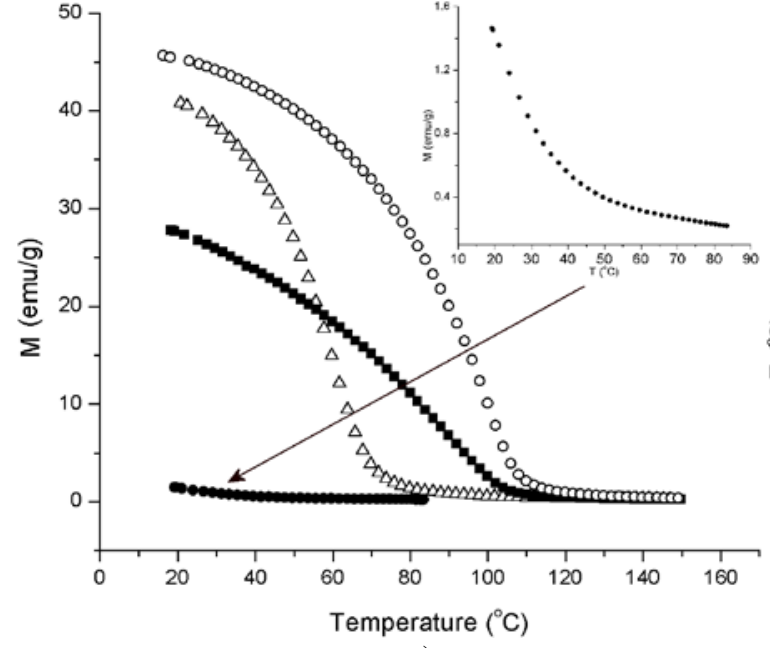

a.)

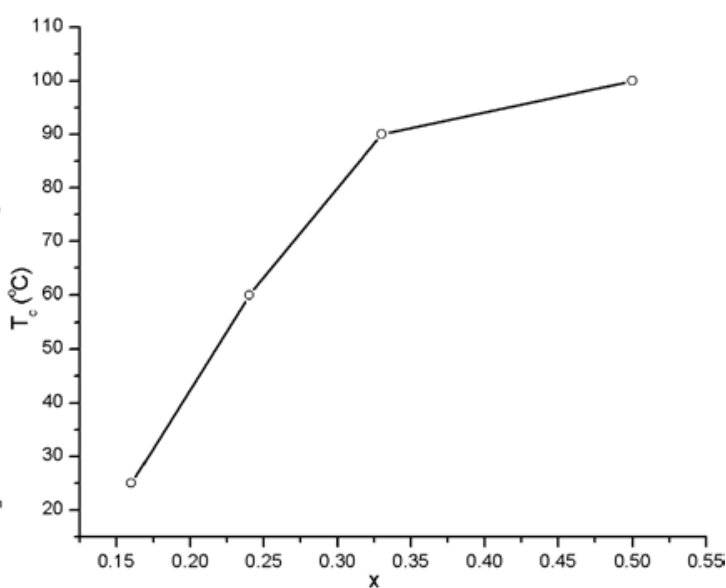

b.) 
Fig. 2. Specific magnetization at $\mathrm{H}=0.1 \mathrm{~T}$ vs. measuring temperature dependencies (a) for the synthesized $\mathrm{La}_{1-\mathrm{x}} \mathrm{Sr}_{\mathrm{x}} \mathrm{MnO}_{3+\delta}$ samples with $\mathrm{x}=0.16(\bullet), 0.24(\Delta), 0.33(\mathrm{o})$ and $0.5(\bullet)$ stoichiometries, all calcined at $1200{ }^{\circ} \mathrm{C}$, and Curie temperature $\left(\mathrm{T}_{\mathrm{c}}\right)$ vs stoichiometric parameter " $\mathrm{x}$ " dependencies (b).

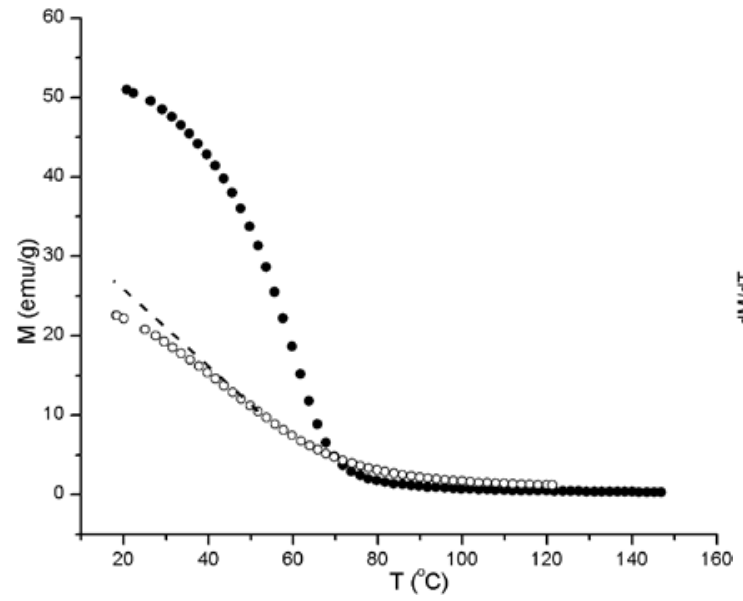

a.)

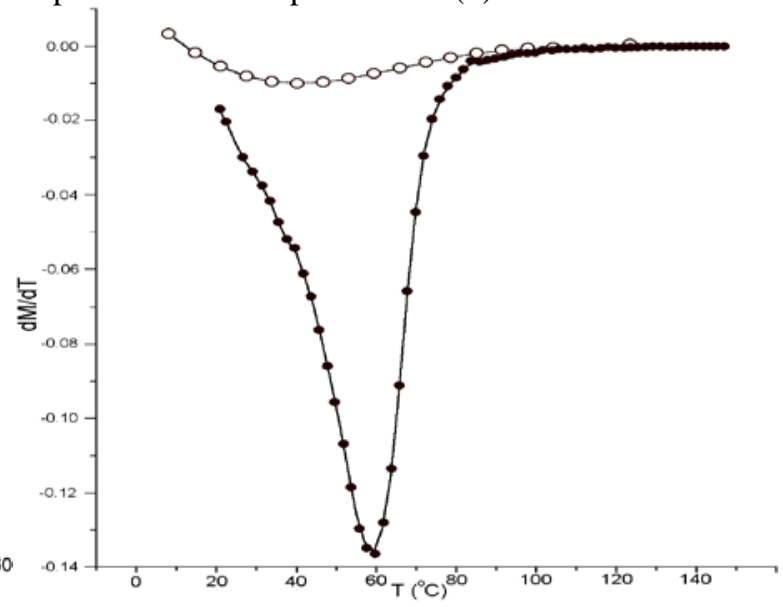

b.)

Fig. 3. Specific magnetization at the $H=0.5 \mathrm{~T}$ (a) and the respective derivatives (b) vs. measuring temperature dependencies for pure $(\Delta, \bullet)$ and silica-coated (o) $x=0.24$ LaSr-manganite sample. $M=f(T)$ dependencies of the milled, silica-uncoated and silica-coated samples diverge according to the dashed line.

From Fig. 3, it can be seen that, comparing to the sample which was a precursor to the milling and coating procedures, silica-coated $\mathrm{La}_{0.76} \mathrm{Sr}_{0.24} \mathrm{MnO}_{3+\delta}$ sample possesses $\mathrm{T}_{\mathrm{C}}$ lower by $\sim 20^{\circ} \mathrm{C}$, when the respective is determined as $\mathrm{dM}^{2} / \mathrm{dT}^{2}=0$ point. However, the milled, silica-coated and silica-uncoated manganite samples only slightly diverge in the respective $M=f(T)$ dependencies, as is obvious from Fig.3. Therefore, since no significant changes in $T_{C}$ with the coating treatment were observed, despite previously observed decreases in $\mathrm{T}_{\mathrm{c}}$ with addition of silica [4] or polymer [5] component, it is the milling treatment and not surface modifications with silica encapsulations, that gives rise to lower Curie point of the final sample comparing to the precursor, pure as-prepared LaSr-manganite.

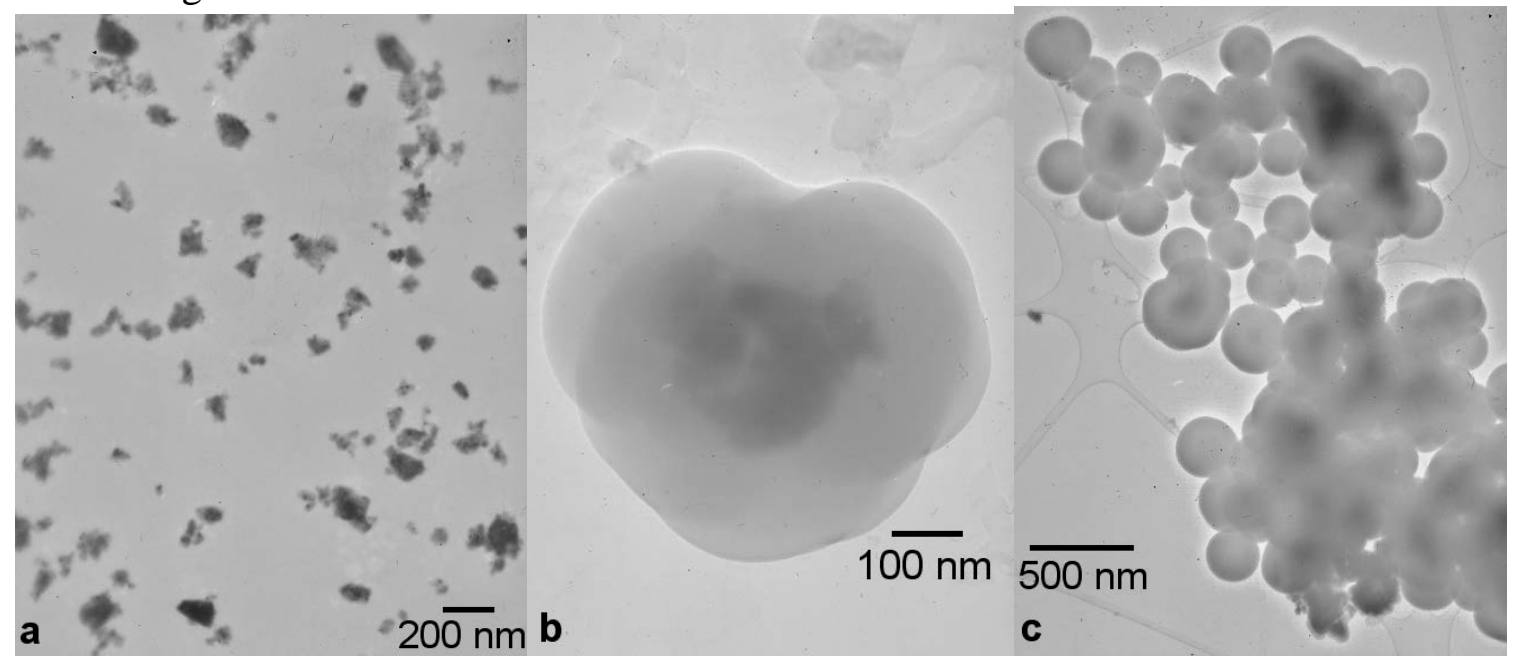

Fig. 4. TEM images of the non-coated (a) and coated (b,c) milled LaSr-manganite powder.

Whereas particles of LaSr-manganite following the milling treatment possess irregular shapes (Fig. 4a) and average $~ 100 \mathrm{~nm}$ in size, an almost uniform particle size 
( $250 \mathrm{~nm}$ ) is observed on TEM images of silica-coated manganite in Fig. 4b,c. Particles of such sizes might be proven advantageous since they are found on "middle ground" between particles with few tens of nanometers in size - hardly withstanding flow dynamics in the circulatory system and difficult to magnetically guide - and micron-sized particles, being normally too large to allow for fine site-specific, in vivo drug delivery. Entirely encapsulated manganite particles within biocompatible silica coatings, evidenced from Fig. 4, would possibly eliminate antigenic effects related to the potential recognition of pure manganite particles in the bloodstream by reticulo-endothelial network, the body's major defence system. Silica coating also offers numerous possibilities of attachment of additional amino, carboxyl and other functional groups to hydroxyl groups on its surface [6,7], enabling further complexification and fine upsurge in both structure and targeting function of the drug-delivery particles.

\section{Conclusions}

The synthesis pathway and some of the basic properties of a material with novel microstructural composition and intended applicative function, has been presented. Simple ways to design the silica-coated material with a desired Curie point for an intended hyperthermic, thermoblastic or drug-delivery application, by varying the stoichiometry of manganite cores of the final particles, are outlined. Investigations of the applied character, concerning behaviour of the system in biological environments, would comprise further steps in developing herein initiated, bio-course in the knowledge on complex chemistry and applied potentials of manganite materials.

\section{References}

1. Q. A. Pankhurst, J. Connolly, S. K. Jones, J. Dobson, J. Phys. D 36 (2003) R167.

2. M. L. Hans, A. M. Lowman, Curr. Opin. Solid State Mater. Sci. 6 (2002) 319.

3. M. Kawashita, Int. J. Appl. Ceram. Tech. 2 (2005) 173.

4. M. Takemoto, K. Yamagiwa, Y. Umeshita, H. Ikawa, Electroceram. Japan IV: Key Eng. Mater. 216 (2002) 145.

5. J. Chatterjee, M. Bettge, Y. Haik, C. J. Chen, J. Magn. Magn. Mater. 293 (2005) 303.

6. C. C. Berry, and A. S. G. Curtis, J. Phys. D 36 (2003) R198.

7. M. L. Vadala, M. A. Zalich, D. B. Fulks, T. G. St. Pierre, J. P. Dailey, J. S. Riffle, J. Magn. Magn. Mater. 293 (2005) 162. 